\title{
Increase of liver GLUT2 protein content in TSOD (Tsumura, Suzuki, Obese Diabetes) mouse, a new genetic animal model of type 2 diabetes
}

\author{
Toshihiro Miura', Motoshi Kato', Naoki Iwamoto', Wataru Suzuki ${ }^{3}$, Torao Ishida ${ }^{2}$ and \\ Keiichiro TANIGAWA ${ }^{1}$ \\ ${ }^{1}$ Department of Clinical Nutrition, Suzuka University of Medical Science, ${ }^{2}$ Hi-tech Research Center, Suzuka University of \\ Medical Science, 1001-1 Kishioka, Suzuka, Mie, 510-0293, Japan, and Tsumura Central Research Laboratories, ${ }^{3}$ Tsumura and \\ Co., 3586 Yoshiwara, Ami-machi, Inashiki-gun, Ibaraki 300-11.
}

(Received 1 August 2001, and acceted 10 August 2001)

\begin{abstract}
In order to elucidate the mechanism of hyperglycemia in TSOD (Tsumura, Suzuki, Obese Diabetes) mouse, a new genetic animal model of type 2 diabetes, we examined the alteration of GLUT2 protein content in liver. The liver type glucose transporter (GLUT2) protein content from mouse liver significantly increased in the TSOD mice when compared to that in normal, Tsumura, Suzuki, Non Obesity (TSNO) mice $(P<0.01)$. The TSOD mouse exhibited a significantly increased blood glucose and serum insulin levels when compared with TSNO mouse. These results suggest that the hyperglycemia of TSOD mouse may be due, at least in part, to the increase of GLUT2 protein.
\end{abstract}

Increased hepatic glucose output is known as one of the major pathogenic factors of type 2 diabetes mellitus, together with insulin resistance in peripheral tissues and impairment of glucoseinduced insulin secretion from pancreatic B cells. In mammalian cells, glucose is transported to cells by diffusion that is facilitated by specific membrane proteins. Molecular cloning studies have delineated a family of genes encoding such glucose transporter proteins $(12,15)$. These glucose transporter isoforms each have tissue specific distributions and play specific roles to differentially regulate glucose uptake in various tissues. The GLUT1 and GLUT2 isoforms mediate transport of glucose into and out of hepatocytes (2). However, GLUT1 is expressed at low levels in the liver.

A mouse strain, Tsumura Suzuki Obese Diabetes (TSOD) mouse, a new genetic type 2 diabetes model which develops moderate degrees of obesity and diabetes that are especially apparent in animals of more than 11 week old. Phenotypic characterization revealed that the
TSOD mouse had reduced insulin sensitivity (13).

However, the change of liver GLUT2 in the TSOD mouse is not known. Therefore, we examined the alteration of GLUT2 protein content in liver in order to elucidate the mechanism of hyperglycemia in this mouse model.

Animals. Male TSOD and TSNO (normal) mice ( 11 weeks old, Clea, Japan) were kept in an experimental animal room for 10 weeks with free access to food and water. The mice were housed individually in an air-conditioned room at an ambient temperature of $24 \pm 2^{\circ} \mathrm{C}$ with a $12 \mathrm{~h}$ light-dark cycle. The mice were given food, $\mathrm{CE}-2$ (Clea, Tokyo, Japan) and water ad libitum.

Determination of blood glucose and serum insulin. Blood samples were withdrawn from the cavernous sinus with a capillary. Blood glucose levels were determined by the glucose oxidase method (4) and serum insulin was measured by the double-antibody method (1). 
Western blot analysis. The liver was resected for the experiment (TSOD and TSNO mice). The antibody used in the Western blotting (East Acres, USA) was raised against a synthetic peptide corresponding to the COOH-terminal domain of mouse GLUT2 (residues 498-522), as reported by Thorens et al. (14) (no reaction against brain, fat, or muscle; does not cross-react with GLUT1 or GLUT4 tested). To prepare the total membrane particulate fractions, mice livers were excised and 1-2 $\mathrm{g}$ of each liver slice was homogenized in $25 \mathrm{~mL}$ of $10 \mathrm{mM}$ Tris- $\mathrm{HCl}, 1 \mathrm{mM}$ phenylmethyl sulphonyl fluoride and 1,000 units/ $\mathrm{mL}$ of aprotinin (9). The homogenates were then centrifuged at $700 \mathrm{~g}$ for $10 \mathrm{~min}$ at $4^{\circ} \mathrm{C}$ to sediment the fraction containing mainly the nuclei and mitochondria. The resulting supernatant was centrifuged at $13,000 \mathrm{~g}$ for $20 \mathrm{~min}$ at $4^{\circ} \mathrm{C}$ to yield a pellet designated as the membrane fraction of the liver in this study. The membrane fractions $(0.1 \mathrm{mg})$ prepared were suspended in 1\% SDS and $50 \mathrm{mM}$ dithiothreitol and subjected to SDSpolyacrylamide (9\%) gel electrophoresis. Electrophoretic transfer to nitrocellulose paper and the detection of an immunocomplex with enhanced chemiluminescence (Amersham, Buckinghamshire, UK) were carried out as previously described (11). The sheet was exposed on RX X-ray film and an intensifying screen (Fuji, Tokyo, Japan). Prestained molecular weight standard (Bio-Rad, Richmond, VA, USA) was used for estimation of the molecular weight. The experiments were performed at least twice for each tissue with similar results.

Statistical analysis. All data are expressed as the mean \pm SEM. Student's $t$ test was used for statistical analysis. Values were considered to be significantly different when $P$ value was less than 0.05 .

Western blot analysis. The hepatic GLUT2 protein content are shown in Fig. 1. Mouse GLUT2 antibody hybridized to 55 kilodalton of protein from the liver of TSOD and TSNO mice. Densitometric scanning of the 55 kilodalton bands revealed that the amount of liver GLUT2 protein in TSOD mice was elevated to $189 \%$ that in TSNO mice $(P<0.01)$.

Blood glucose and serum insulin. As shown in Table 1, the body weight, blood glucose and insulin level in basal stage were significantly elevated in diabetic TSOD mice $(P<0.01)$.

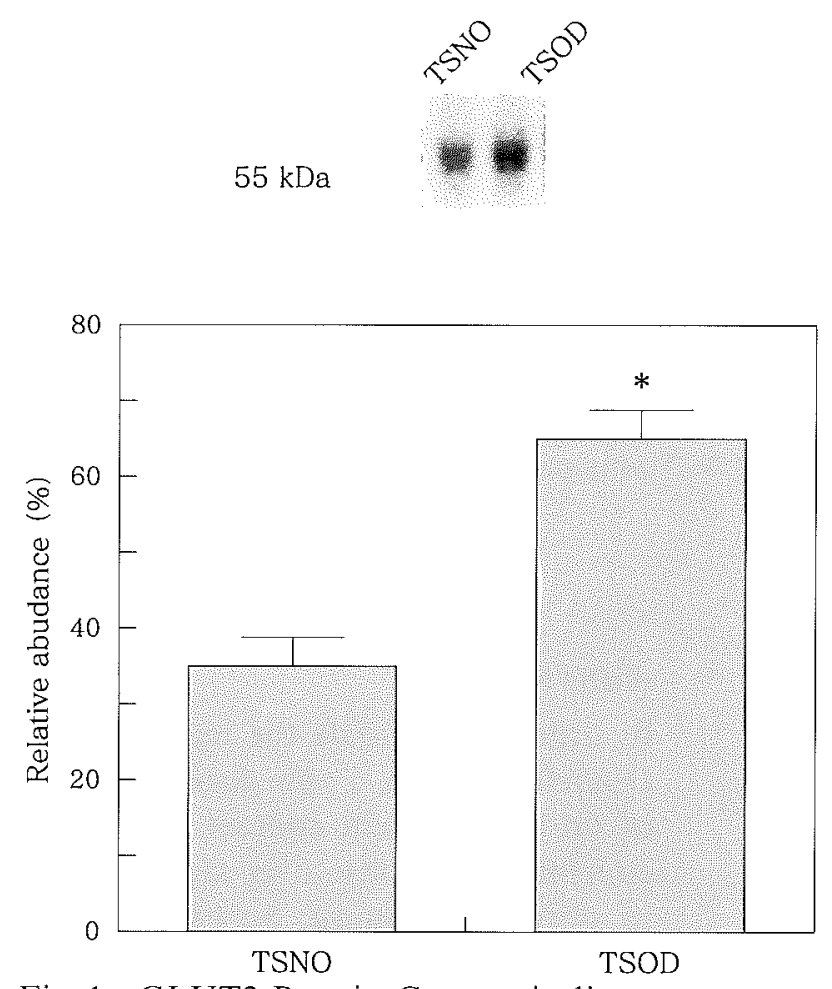

Fig. 1 GLUT2 Protein Content in liver.

Western blot analysis of GLUT2 protein content in $50 \mu \mathrm{g}$ cellular protein was done from livers of TSNO and TSOD mice, followed by quantitation of GLUT2 protein content abundance in the liver. Autoradiographic bands from hybridizations shown were quantitated by densitometry. Each value represents the mean $\pm \operatorname{SEM}(\mathrm{N}=4)$. Significantly different from TSNO, $* P<0.01$.

We examined the GLUT2 glucose transporter in TSOD mouse liver, since it has been reported that GLUT2 plays a crucial role in the liver process of glucose output and intake $(2,9)$. In previous study, we investigated that adrenaline (inducer of hepatic glucose production) increased GLUT2 protein content in normal mice liver (6). Similar effects have been reported by Miura et al. (5) and Ohnishi et al. (10) From these findings, it seems that the glucose production in liver is mediated by GLUT2 glucose transporter.

Blood glucose and serum insulin level significantly increased in TSOD mice when compared with TSNO mice. TSOD mice were known to belong to genetically-induced diabetes including ob/ob mice (7) and KK mice (8). TSOD mice show hyperinsulinemia as a result of insulin resistance (13). Insulin resistance in type 2 diabetes mellitus is mostly to decreased stimula- 
Table 1 Body weight, Blood glucose and Insulin

\begin{tabular}{|c|c|c|c|}
\hline & Body weight $(\mathrm{g})$ & Blood glucose $(\mathrm{mg} / \mathrm{dL})$ & Insulin $(\mu \mathrm{U} / \mathrm{mL})$ \\
\hline TSNO & $39.2 \pm 0.7$ & $166 \pm 7$ & $30 \pm 2$ \\
TSOD & $56.6 \pm 1.2^{*}$ & $495 \pm 26^{*}$ & $177 \pm 12^{*}$ \\
\hline
\end{tabular}

Each value represents the mean \pm s. E. from 5 mice.

Significantly different from TSNO, ${ }^{*} P<0.001$.

tion of glycogen synthesis by insulin. In muscle, a deficiency in the GLUT4 glucose transporter is responsible for hyperglycemia in type 2 diabetes (3). However, in liver, elevated GLUT2 glucose transporter was caused by hyperglycemia due to increased hepatic glucose production. Yamamoto et al. (16) have shown that elevated GLUT2 mRNA expression in the liver may increase hepatic glucose production in Wistar fatty rats. These findings suggest that hepatic glucose production increases in TSOD mouse.

\section{REFERENCES}

1. Bailei, C. J., Ahmed-Sorour, H. (1980) Role of ovarian hormones in the long-term control of glucose hemeostasis. Diabetologia, 19, 475-480.

2. Bell, G. I., Kayano, T., Buse, J. B., Burant, C. F., Takeda, J., Lin, D., Fukumoto, H., Seino, S. (1990) Molecular biology of mammalian glucose transporters. Diabetes Care, 13, 198-208.

3. Cline, G. W., Petersen, K. F., Krssak, M., Shen, J., Hundal, R. S., Trajanoski, Z., Inzucchi, S., Dresner, A., Rothman, D. L., Shulman, G. I. (1999) Inpaired glucose transport as a cause of decreased insulin-stimulated muscle glycogen synthesis in type 2 diabetes. N. Engl. J. Med., 341, 240-246.

4. Marks, V., Lloyd, K. (1963) Preservation of blood glucose analysis by glucose oxidase. Clin. Chem. Acta., 8, 326.

5. Miura, T., Kato, A., Usami, M., Kadowaki, S., Seino, Y. (1995) Effect of Polygonati Rhizoma on blood glucose and facilitative glucose transporter isoform 2 (GLUT2) mRNA expression in Wistar fatty rats. Biol. Pharm. Bull., 18, 624-625.

6. Miura, T., Kato, M., Iwamoto, N., Yamada, Y., Ishida, T., Seino, Y,, Tanigawa, K. (2000) Effect of epinephrine on
GLUT2 protein content in mouse liver. Biol. Pham. Bull,, 23, 1374-1376.

7. Nakamura, M. (1962) A diabetic strain of the mouse. Proc. Jpn. Acad., 38, 348-352.

8. Nishimura, M. (1969) Breeding of mice strain for diabetic mellitus. Exp. Animal, 18, 147-157.

9. Oka, Y., Asano, T., Shibasaki, T. (1990) Increased liver glucose transporter protein and mRNA in streptozotocininduced diabetic rats. Diabetes, 39, 441-446.

10. Ohnishi, Y., Takagi, S., Miura, T., Usami, M., Kako, M., Ishihara, E., Yano, H., Tanigawa, K., Seino, Y. (1996) Effect of Ginseng Radix on GLUT2 protein content in mouse liver in normal and epinephrine-induced hyperglycemic mice. Biol. Pharm. Bull., 19, 1238-1240.

11. Perez, C., Albert, I., DeFay, K., Zachariades, N.,Gooding, L., Michael, K. (1990) A nonsecretable cell surface mutant of tumor necrosis factor (TNF) kills by cell-to-cell contact. Cell, 63, 251-258.

12. Simpson, I. A., Cushman, S. W. (1986) Hormonal regulation of mammalian glucose transport. Ann. Rev. Biochem., 55, 1059-1089.

13. Suzuki, W., Ilzuka, S., Tabuchi, M., Funo, S., Yanagisawa, T., Kimura, M. (1999) A new mouse model of spontaneous diabetes derived from ddY strain. Exp. Anim., 48, 181-189.

14. Thorens, B., Sarkar, H. K., Kaback, H. R., Lodish, H. F. (1988) Cloning and functional expression in bacteria of a novel glucose transporter present in liver, intestine, kidney, and beta-pancreatic islet cells. Cell, 55, 281-290.

15. Wheeler, T. J., Hinkle, P. C. (1985) The glucose transporter of mammalian glucose cells. Annu. Rev. Physiol., 47, 503-517.

16. Yamamoto, T., Fukumoto, H., Koh, G., Yano, H., Yasuda, K., Masuda, K., Ikeda, H., Imura, H., Seino, Y. (1991) Liver and muscle-fat type glucose transporter gene expression in obese and diabetic rats. Biochem. Biophys. Res. Conmun., 175, 995-1002. 